\title{
Propriedades físicas do solo e sistema radicular do cacaueiro, da pupunheira e do açaizeiro na Amazônia oriental
}

\author{
Paulo Fernando da Silva Martins ${ }^{1}$, Sebastião Geraldo Augusto ${ }^{2}$
}

\section{RESUMO}

O conhecimento das relações entre raízes das culturas e propriedades físicas do solo é de grande importância para o manejo adequado. Esta pesquisa avalia a distribuição das raízes das culturas do cacaueiro, da pupunheira e do açaizeiro, relacionando com as propriedades físicas do solo. O estudo foi desenvolvido em Latossolo Amarelo álico, e as amostras de raízes e de solos foram retiradas a cada $10 \mathrm{~cm}$ até $40 \mathrm{~cm}$. O delineamento experimental utilizado para cada cultura foi em blocos ao acaso, em esquema fatorial (quatro profundidades e três classes de raízes), com quatro repetições. As amostras de raízes foram obtidas em monólitos e em dois pontos de distância entre as fileiras das plantas, separadas em três classes de diâmetro: < 1,0 mm, 1,0-3,0 mm e > 3,0 mm. O açaizeiro apresentou o dobro de raízes da pupunheira e 10 vezes mais que do cacaueiro. Entre as distâncias das plantas não houve diferença na quantidade de raízes da pupunheira. Houve correlação direta entre a quantidade de raízes, das três culturas, e o teor de areia grossa, e inversa com a densidade do solo e o teor de argila. O volume de poros grandes teve correlação direta com a quantidade de raízes do cacaueiro e do açaizeiro nas três classes de diâmetro. O açaizeiro, além de possuir o sistema radicular mais abundante, apresenta o maior número de correlações entre a quantidade de raízes e as propriedades físicas do solo, envolvendo as três classes de diâmetro de raízes.

Palavras-chave: diâmetro de raízes, latossolo, porosidade.

\section{ABSTRACT}

\section{Physical properties of soil and root system of cocoa, peach palm and açai in the eastern Amazon}

The knowledge on the relationship between roots of crop plants and soil physical properties is very important. This article evaluates the distribution of the root systems of cocoa, palm peach and açai and their relationships with the soil physical properties. The research was carried out in an alic Yellow Latosol and root and soil samples were obtained from $10 \mathrm{~cm}$ to $40 \mathrm{~cm}$ depth. The experiment was arranged in a randomized block in the factorial design (four depth soils and three root class), with four replications. The açai root amount is twice of the palm peach and ten times more that of cacao. No difference was verified in the amount of roots of peach between the distances of the plants. The roots were collected in two distances of the plant stem in monolith samples and separated in three diameter class: $<1.0 \mathrm{~mm}, 1.0-3.0$ $\mathrm{mm}$ e $>3.0 \mathrm{~mm}$. The roots amount of the three plants was directly correlated with the coarse sand content and inversely correlated with clay content and bulk density. The large pores size was also directly correlated with the amount of cacao and açai roots in the three classes of diameter. The açai showed the most abundant root system and it the greatest number of correlations between the amount of roots and the physical properties of soil involving the three diameter root classes.

Key words: diameter roots, yellow latosol, porosity.

Recebido para publicação em 19/09/2011 e aprovado em 11/09/2012.

${ }^{1}$ Engenheiro-Agrônomo, Doutor. Núcleo de Ciências Agrárias e Desenvolvimento Rural, Universidade Federal do Pará, Rua Augusto Corrêa 01, Guamá, 66075-110, Belém, Pará, Brasil.pfsm@ufpa.br (autor para correspondência).

${ }^{2}$ Engenheiro-Agrônomo, Doutor. Núcleo de Ciências Agrárias e Desenvolvimento Rural, Universidade Federal do Pará, Campus Altamira, Rua José Porfirio, 2515, São Sebastião, 68370-000, Altamira, Pará, Brasil. saugusto@ufpa.br 


\section{INTRODUÇÃO}

O desenvolvimento das culturas não depende tão somente da presença dos nutrientes, mas do ambiente favorável em que se encontram em termos de movimentação da água, do ar e regime térmico. Esse ambiente é favorável quando o solo é bem estruturado, permitindo espaços porosos para o desenvolvimento das raízes (Selton et al., 2008), condição necessária para que possam absorver os nutrientes. Como, além do genótipo, o crescimento e a distribuição das raízes são determinados pelas condições ambientes e de cultivo, as propriedades físicas do solo estão diretamente relacionadas.

O estudo da distribuição das raízes é um fator de grande importância, já que o seu conhecimento permite melhor planejamento das práticas de adubação, irrigação e outros tratos culturais, assim como a utilização dos maquinários. Ademais, fornece informações sobre a competição por água e nutrientes entre as plantas de uma cultura ou de diferentes culturas em sistemas de consórcio (Haag, 1997). Avaliando a distribuição das raízes de pupunheira, em consórcio com outras culturas, em ambiente amazônico, este autor verificou que a distribuição das raízes é bastante variável tanto em profundidade como em relação à distância da base da planta.

Além de serem espécies frutíferas, como o cacaueiro, a pupunheira e o açaizeiro cultivados são importantes pela produção de palmito. A importância dessas culturas pode ser expressa pela produção anual na região norte, segundo IBGE (2006), que é de 190 t de amêndoas de cacau; 3,6 $\mathrm{t}$ de cachos de pupunha, cujo peso por cacho pode variar de 2 a $12 \mathrm{~kg}$ (Shanley \& Medina, 2005); $168 \mathrm{t}$ de frutos de açaí; e 32,4 t de palmito (cuja espécie de origem não foi possível identificar). Essas quantidades correspondem a $16,4 \%$ da produção brasileira de cacau, $4,7 \%$ de palmito, $45,2 \%$ de pupunha e $97,7 \%$ de açaí.

Por outro lado, ainda pouco se conhece sobre a distribuição das raízes dessas culturas e das relações com as propriedades físicas do solo. O presente trabalho caracteriza a distribuição das raízes do cacaueiro, da pupunheira e do açaizeiro, em cultivos solteiros, relacionando com as propriedades físicas do solo.

\section{MATERIAL E MÉTODOS}

A pesquisa foi conduzida na Estação de Recursos Genéticos do Cacau, em janeiro de 2000. O solo da área do experimento era o Latossolo Amarelo álico, de textura franco-arenosa, com alta saturação de alumínio (80\%) e mosqueados abundantes no perfil (Neves \& Barbosa, 1983), indicativos de alagamento no período chuvoso.

O delineamento experimental para cada cultura foi em blocos ao acaso, no esquema fatorial de quatro profundidades e três classes de raízes, com quatro repetições. A análise estatística constou da análise de variância utilizando o software SAS (Statistic Analisys System). Foi efetuada a comparação entre a quantidade de raízes entre duas distâncias em relação ao tronco da planta (D1 e D2). A hipótese de nulidade foi rejeitada sempre que a probabilidade foi inferior a $5 \%$. As raízes foram coletadas considerando duas distâncias em relação á base da planta, as quais foram avaliadas por profundidade em cada distância independentemente. Foi verificada a relação entre quantidade de matéria seca de raízes, considerando a média entre as duas distâncias da base das plantas de cada cultura, e as variáveis físicas do solo, por meio da correlação parcial de Pearson.

As culturas, com oito anos de idade, foram cultivadas nas seguintes condições: cacaueiro (Theobroma cacao L.) em cultivo solteiro, sombreado provisoriamente com bananeira (Musa ssp.), com desbaste anual das plantas para redução de aproximadamente $25 \%$ do stand, após o $1^{\circ}$ ano de plantio - permanecendo no máximo quatro por touceira - até a completa supressão no $5^{\circ}$ ano e sombreamento permanente com eritrina (Erytrina paepigiana asileira), espaçamento $3,0 \mathrm{~m} \times 3,0 \mathrm{~m}$, totalizando 104 plantas em uma área de $936 \mathrm{~m}^{2}$; pupunheira (Bactris gaesipaes H. B. K.) em cultivo solteiro, espaçamento de 3,0 m x 1,5 m, totalizando 195 touceiras em uma área de $877,5 \mathrm{~m}^{2}$ e sombreamento permanente com gliricidia, como fonte de biomassa, por meio de poda duas vezes por ano - remoção total dos ramos; e açaizeiro (Euterpe oleraceae Mart.) em cultivo solteiro no espaçamento de 3,0 m x 1,5 m, totalizando 195 touceiras em uma área de $877,5 \mathrm{~m}^{2} \mathrm{e}$ sombreamento permanente com gliricidia, do mesmo modo que no da pupunheira. As três culturas receberam somente uma fertilização, com $5 \mathrm{~kg}$ de adubo orgânico (cama de aviário) por planta, aplicado quatro anos antes do início do experimento.

As raízes foram retiradas em monólitos (Bohm, 1979) entre as plantas na linha de plantio, em trincheiras de 1,5 $\mathrm{m}$ de profundidade. Os pontos de coleta dos monólitos foram de 0,50 m (distância D1) e 1,50 m (distância D2) de cada lado das plantas de cacaueiro, e de 0,25 m (distância D1) e 0,75 m (distância D2) de cada lado das plantas de açaizeiro e de pupunheira.

As raízes foram separadas utilizando peneiras com malha de $2 \mathrm{~mm}$, em água corrente, com o auxílio de pinças, em três classes de diâmetro: < 1,0 mm, 1,0-3,0 mm e > 3,0 $\mathrm{mm}$. Após a secagem em estufa por $48 \mathrm{~h}$ a $60^{\circ} \mathrm{C}$, foi determinada a massa seca de raízes por volume de solo $\left(\mathrm{g} \mathrm{dm}^{-3}\right)$, também denominada densidade de raízes (Bovi et al., 1999; Chaimsohn et al., 2007).

As amostras de solos foram coletadas nos mesmos locais e simultaneamente às coletas das raízes, nas profundidades de 0-10, 10-20, 20-30 e 30-40 cm. Foram determinados os teores das frações granulométricas (areia gros- 
sa, areia fina, silte e argila) e o grau de floculação $\left(\mathrm{g} \mathrm{kg}^{-1}\right)$, a densidade de partícula e a do solo $\left(\mathrm{kg} \mathrm{m}^{-3}\right)$, a condutividade hidráulica do solo saturado $\left(\mathrm{m} \mathrm{h}^{-1}\right)$ e o volume de poros de diversos tamanhos de diâmetro $(>0,15$ $\mathrm{mm},>0,05 \mathrm{~mm},>0,03 \mathrm{~mm},<0,03 \mathrm{~mm},<0,05 \mathrm{~mm}$, expresso $\mathrm{em} \mathrm{m} \mathrm{m}^{3} \mathrm{~m}^{-3}$.

\section{RESULTADOS E DISCUSSÃO}

A massa seca de raízes do cacaueiro variou de $0,46 \mathrm{~g}$ $\mathrm{dm}^{-3}$ a 2,09 $\mathrm{g} \mathrm{dm}^{-3}$ na profundidade de $0-10 \mathrm{~cm}$, e de $0,02 \mathrm{~g}$ $\mathrm{dm}^{-3}$ a $0,10 \mathrm{~g} \mathrm{dm}^{-3}$ na profundidade de $30-40 \mathrm{~cm}$ (Tabela 1 ). A quantidade de raízes na distância D1 $(0,50 \mathrm{~m})$ é maior nas classes de 1,0-3,0 mm e > 3,0 mm de diâmetro nas profundidades de 0-10 e 10-20 cm. Na distância D2, a quantidade de raízes é maior na profundidade de $0-10 \mathrm{~cm}$ da classe > 3,0 mm em relação às demais profundidades, enquanto nas duas outras classes de tamanho é maior na superfície em relação às profundidades de 20-30 e 30-40 $\mathrm{cm}$. A quantidade de raízes é maior na D1 que na D2 na profundidade $10-20 \mathrm{~cm}$ da classe de $1,0-3,0 \mathrm{~mm}$ e na D2 que na D1 em profundidade de $0-10 \mathrm{~cm}$ da classe $>3,0 \mathrm{~mm}$. A quantidade acumulada de raízes de 0 a $40 \mathrm{~cm}$ somente foi maior na distância D1 que na D2 na classe 1,0-3,0 mm de diâmetro.

Silva (2009), estudando cacaueiros de seis a sete anos de idade, no Sul da Bahia, encontrou valor médio de 0,75 tha $^{-1}$ de biomassa seca de raízes com diâmetro menor que $1,0 \mathrm{~mm}$ até $50 \mathrm{~cm}$ de profundidade, correspondendo a $15 \mathrm{~g}$ $\mathrm{dm}^{-3}$. Cotta et al. (2008) indicam, para cacaueiros também de seis anos de idade, cultivado em consórcio com seringueira no Estado da Bahia, quantidade de $2,57 \mathrm{~kg}$ por planta em uma área de amostragem de $3 \mathrm{~m}^{2}$ até $50 \mathrm{~cm}$ de profundidade, o que corresponderia a algo em torno de $0,38 \mathrm{~g} \mathrm{dm}^{-3}$. O valor encontrado por Silva (2009) é bem superior ao de $1,73 \mathrm{~g} \mathrm{dm}^{-3}$ obtido até $40 \mathrm{~cm}$ de profundida- de deste estudo (Tabela 1), enquanto o valor encontrado por Cotta et al. (2008) é bem inferior. Essas diferenças podem ser atribuídas nos dois casos ao método de coleta e a diferenças de meio ambiente, e no segundo também ao consorciamento do cacaueiro.

Na pupunheira, a quantidade variou de $1,75 \mathrm{~g} \mathrm{dm}^{-3} \mathrm{a}$ $9,92 \mathrm{~g} \mathrm{dm}^{-3}$ na profundidade de $0-10 \mathrm{~cm}$ e de $0,05 \mathrm{~g} \mathrm{dm}^{-3} \mathrm{a}$ $0,40 \mathrm{~g} \mathrm{dm}^{-3}$ na profundidade de $30-40 \mathrm{~cm}$ (Tabela 2). Tanto na distância D1 como na D2 a quantidade de raízes é maior nas classes de 1,0-3,0 mm e > 3,0 mm na profundidade de $0-10 \mathrm{~cm}$, não tendo havido diferença na classe $<1,0 \mathrm{~mm}$. Para as distâncias não houve diferença entre as profundidades. Nesta cultura, muito embora o sistema radicular possa chegar até $1,50 \mathrm{~m}$ de raio em torno da touceira e atingir $200 \mathrm{~cm}$ de profundidade (Ferreira et al., 1980), concentra nos $20 \mathrm{~cm}$ superficiais de 58 a 75\% da massa radicular (Previtali, 2007). Vega et al. (2005) verificaram que, além das raízes dessa cultura concentrarem-se na profundidade de 0-20 $\mathrm{cm}$ do solo, ocorrem em maior intensidade na distância mais próxima da base da planta.

A pupunheira produz palmito com dois anos e frutos a partir de três, produção que estabiliza após o sexto ano (Shanley \& Medina, 2005). Chaimsohn et al. (2007) verificaram, em plantas de pupunha cultivadas na Costa Rica, que um ano e nove meses após o plantio a quantidade de raízes variou, de acordo com a aplicação trimestral de fertilizante, de 0,44 a $1,73 \mathrm{~g} \mathrm{dm}^{-3}$ de raízes $<1,0 \mathrm{~mm}$ e de 0,90 a 3,00 $\mathrm{g} \mathrm{dm}^{-3}$ de raízes $>1,0 \mathrm{~mm}$. Esses autores não encontraram diferenças quanto à distância em relação à base da touceira entre plantas $(50 \mathrm{~cm})$ ou entre filas $(40 \mathrm{~cm}$ e 60 $\mathrm{cm}$ ) nas raízes $<1,0 \mathrm{~mm}$ que atingiram valor um pouco maior que $1 \mathrm{~g} \mathrm{dm}^{-3}$, relativamente próximo ao encontrado neste estudo, em torno de 2,6 $\mathrm{dm}^{-3}$ (Tabela 2). Já para as raízes > 1,0 mm, os autores citados encontraram 3,00 g

Tabela 1. Massa seca de raízes por diâmetro em diferentes profundidades e distâncias (D1 e D2) da planta de cacaueiro

\begin{tabular}{|c|c|c|c|c|}
\hline \multirow{3}{*}{ Profundidade } & \multirow{3}{*}{ Distância } & \multicolumn{2}{|c|}{ Massa seca $\left(\mathrm{g} \mathrm{dm}^{-3}\right)$} & \multirow[b]{2}{*}{$>3,0 \mathrm{~mm}$} \\
\hline & & $<1,0 \mathrm{~mm}$ & $1,0-3,0 \mathrm{~mm}$ & \\
\hline & & \multicolumn{3}{|c|}{$\mathrm{g} \mathrm{dm}^{-3}$} \\
\hline $0-10$ & D1 & $0,80 \mathrm{~A} \mathrm{a}$ & $0,74 \mathrm{~A} \mathrm{a}$ & $0,64 \mathrm{~A} \mathrm{~b}$ \\
\hline $10-20$ & & $0,60 \mathrm{ABa}$ & $0,77 \mathrm{~A} \mathrm{a}$ & $0,78 \mathrm{Aa}$ \\
\hline $20-30$ & $(0,50 \mathrm{~m})$ & $0,23 \mathrm{ABa}$ & $0,18 \mathrm{Ba}$ & $0,11 \mathrm{Ba}$ \\
\hline \multirow[t]{2}{*}{$30-40$} & & $0,10 \mathrm{ABa}$ & $0,10 \mathrm{Ba}$ & $0,02 \mathrm{Ba}$ \\
\hline & Total D1 & $1,72 \mathrm{a}$ & $1,78 \mathrm{a}$ & $1,54 \mathrm{a}$ \\
\hline $0-10$ & & $1,09 \mathrm{~A} \mathrm{a}$ & $0,46 \mathrm{Aa}$ & $2,09 \mathrm{~A} \mathrm{a}$ \\
\hline $10-20$ & D2 & $0,53 \mathrm{ABa}$ & $0,40 \mathrm{ABb}$ & $0,23 \mathrm{Ba}$ \\
\hline $20-30$ & $(1,50 \mathrm{~m})$ & $0,07 \mathrm{Ba}$ & $0,04 \mathrm{Ba}$ & $0,04 \mathrm{Ba}$ \\
\hline \multirow[t]{2}{*}{$30-40$} & & $0,06 \mathrm{Ba}$ & $0,02 \mathrm{Ba}$ & $0,02 \mathrm{Ba}$ \\
\hline & Total D2 & $1,74 \mathrm{a}$ & $0,91 \mathrm{~b}$ & $2,37 \mathrm{a}$ \\
\hline
\end{tabular}

Médias seguidas de mesma letra maiúscula na coluna, comparando as profundidades, e minúsculas na linha, comparando as distâncias, não diferem entre si a $5 \%$ de probabilidade de erro. 
$\mathrm{dm}^{-3}$ entre plantas e $1,32 \mathrm{~g} \mathrm{dm}^{-3}$ entre filas, valores bem inferiores à média das distâncias para os tamanhos de raízes equivalentes deste estudo. Essas diferenças podem ser atribuídas às diferenças de idade das plantas e de meio ambiente.

Estudando a quantidade total de raízes de três progênies de pupunheira, de dois anos, em relação à adubação, Bovi et al. (1999), em Ubatuba-SP, encontraram, na profundidade de 0-20 cm, valores médios de $4,24 \mathrm{~g} \mathrm{dm}^{-3}$, sem aplicação de adubo, até $5,33 \mathrm{~g} \mathrm{dm}^{-3}$, com a dose de $200 \mathrm{~kg}$ de $\mathrm{K}_{2} \mathrm{O}$ ha $^{-1}$, diferindo entre os locais de coleta. Esses valores são bem inferiores aos encontrados neste trabalho, que situaram em torno de $20 \mathrm{~g} \mathrm{dm}^{-3}$ na profundidade correspondente, mas que se justifica pela diferença de idade das plantas e de meio ambiente. Considerando as quantidades de raízes encontrada por Bovi et al. (1999), em torno de $4 \mathrm{~g} \mathrm{dm}^{-3}$, sem adubação aos dois anos, e de 20 $\mathrm{g} \mathrm{dm}^{-3}$, aos oito, deste artigo, é de se esperar uma taxa de crescimento anual de raízes de 2,7 nesse período de crescimento da pupunheira.

A quantidade de raízes do açaizeiro é bastante variável com a profundidade, de $6,22 \mathrm{~g} \mathrm{dm}^{-3} \mathrm{a} 17,94 \mathrm{~g} \mathrm{dm}^{-3}$, na profundidade de $0-10 \mathrm{~cm}$, e de $0,28 \mathrm{~g} \mathrm{dm}^{-3} \mathrm{a} 1,53 \mathrm{~g} \mathrm{dm}^{-3}$, na profundidade de $30-40 \mathrm{~cm}$ (Tabela 3). Nas duas distâncias consideradas, a quantidade de raízes das três classes de tamanho é, em geral, superior na profundidade de 0-10 $\mathrm{cm}$ em relação às demais. Somente na distância mais longe do tronco a quantidade de raízes na profundidade de 0-10 $\mathrm{cm}$ da classe $>3,0 \mathrm{~mm}$ é inferior a sua correspondente mais próxima do tronco.

Os resultados obtidos na pesquisa demonstraram que o cacaueiro, que é uma planta dicotiledônea, apresenta variação na distribuição das raízes mais acentuada em profundidade na distância mais afastada da planta e na classe de 1,0-3,0 mm de diâmetro das raízes (Tabela 1). Nas duas outras culturas, que são monocotiledôneas, a variação é semelhante entre as distâncias, mas no açaizeiro a variação é mais evidente na camada superficial nas classes de menor e intermediário diâmetro das raízes, enquanto na classe de diâmetro maior a diminuição é mais reduzida com a profundidade (Tabela 3). Já na pupunheira, a diminuição é sempre na camada superficial, em relação às demais, e restrita às classes de raízes de maior diâmetro (Tabela 2).

Nas três culturas, a quantidade de raízes decresce com a profundidade, porém as diferenças ocorrem sobretudo na profundidade de 0-10 cm para baixo. Entre as distâncias, as diferenças encontradas referem-se apenas à supremacia dessa camada superficial na classe $>3,0 \mathrm{~mm}$, sendo maior na distância mais afastada da planta do cacaueiro e mais próxima da do açaizeiro, o que indica haver, entre essas duas culturas, diferenças na distribuição de raízes de maior diâmetro.
Comparando-se todas as classes de diâmetro das raízes, verifica-se que o açaizeiro possui maior quantidade de raízes por volume de solo, praticamente o dobro da quantidade da pupunheira, e 10 vezes mais do que a do cacaueiro. As palmeiras, sendo plantas monocotiledôneas, possuem maior quantidade de raízes grossas e fibrosas que as dicotiledôneas, por isso são menos eficientes na absorção de nutrientes, o que pode ser compensado por maior quantidade (Bovi et al., 1999).

Quando se compara a quantidade de raízes por classe de diâmetro, verifica-se que, em todas as classes, o açaizeiro tem maior quantidade de raízes que a pupunheira. Em relação ao cacaueiro, a quantidade é diferenciada em razão do diâmetro das raízes, chegando a ser 14 vezes maior na classe > 3,0 mm. A comparação entre a quantidade de raízes do cacaueiro e da pupunheira indica que esta possui de duas a seis vezes mais raízes, sendo a variação mais acentuada nas duas classes de maior diâmetro.

Considerando as raízes $<1,0 \mathrm{~mm}$, pela importância que possuem na absorção dos nutrientes, encontra-se na Figura 1 a distribuição dessas raízes nas culturas estudadas, expressando a quantidade de matéria seca, em $\mathrm{g} \mathrm{m}^{-2} \mathrm{dm}^{-1}$, o que permite a comparação direta com os dados obtidos por Haag (1997). Verifica-se que o padrão de distribuição é semelhante entre as culturas, apesar de o açaizeiro possuir uma quantidade de raízes muito superior ao das duas outras culturas. Assim como nas demais classes de diâmetro, há forte diminuição da quantidade de raízes em profundidade e concentração de mais da metade das raízes na profundidade de 0-10 $\mathrm{cm}$. A diminuição da quantidade de raízes da pupunheira é bem mais pronunciada queda das demais, chegando a $355 \mathrm{~g} \mathrm{~m}^{-2} \mathrm{dm}^{-1}$ na profundidade de $0-10 \mathrm{~cm}$ para $10 \mathrm{~g} \mathrm{~m}^{-2}$ $\mathrm{dm}^{-1}$ na profundidade de $30-40 \mathrm{~cm}$. Por outro lado, o cacaueiro é o que apresenta distribuição mais uniforme em profundidade.

Haag (1997), estudando pupunheiras com idade de seis anos, implantadas em Latossolo Amarelo argiloso da Amazônia Central, encontrou quantidade de raízes $<1,0$ $\mathrm{mm}$, que variou de 170 a $300 \mathrm{~g} \mathrm{~m}^{-2} \mathrm{dm}^{-1}$ na profundidade de $0-10 \mathrm{~cm}$ do solo e em torno de $50 \mathrm{~g} \mathrm{~m}^{-2} \mathrm{dm}^{-1}$ na profundidade de $10-30 \mathrm{~cm}$. Na presente pesquisa, constata-se uma quantidade de raízes nessa mesma classe de diâmetro um pouco superior $\left(345 \mathrm{~g} \mathrm{~m}^{-2} \mathrm{dm}^{-1}\right.$ na profundidade de $0-10$ $\mathrm{cm}$ e média de $83 \mathrm{~g} \mathrm{~m}^{-2} \mathrm{dm}^{-1}$ entre as profundidades de 10 20 e $20-30 \mathrm{~cm}$ ), diferenças que podem ser explicadas pela diferença de idade das plantas e da textura do solo, muito embora não se possa afastar a existência de desigualdade devido à composição espacial das plantas, já que no trabalho de Haag (1997) tratava-se de fileiras de pupunheiras intercaladas com as culturas de castanha do Brasil, cupuaçu e urucum. 
A Tabela 4 permite uma avaliação global das relações existentes entre a quantidade de matéria seca das raízes das culturas, nas três classes de diâmetro estudadas, e as variáveis físicas do solo.

No cacaueiro, verifica-se que houve correlação positiva da quantidade de matéria seca com o teor de areia grossa, nas três classes de raízes, enquanto com o silte e a argila foi negativa e no caso do silte ausente na classe de 1,0-3,0 mm. Também houve correlação negativa da quantidade de raízes dessa cultura com o grau de floculação na classe de 1,0-3,0 mm e com a densidade do solo nas classes $<1,0 \mathrm{~mm}$ e $>3,0 \mathrm{~mm}$. Com os volumes dos poros do solo por tamanho, a correlação com a quantidade de matéria seca foi sempre positiva, porém significativa apenas no caso das classes $>0,15 \mathrm{~mm},>0,05 \mathrm{~mm}$ e $>0,03 \mathrm{~mm}$, que correspondem aos poros grandes em todas as classes de diâmetro de raízes, não tendo havido correlação com o volume de poros $<0,03 \mathrm{~mm}$ e $<0,05 \mathrm{~mm}$, que corresponde aos poros pequenos.

$\mathrm{Na}$ pupunheira, as relações encontradas diferem das verificadas com o cacaueiro, pelo fato de haver correlação significativa da quantidade de matéria seca com o teor de areia fina, que só não ocorreu na classe de raízes > $3 \mathrm{~mm}$. Além dessa diferença, houve correlação negativa da densidade do solo na classe de raízes $>3 \mathrm{~mm}$ e não ocorreu na classe $<1 \mathrm{~mm}$, enquanto houve correlação positiva com a condutividade hidráulica do solo saturado nas classes de raízes de 1-3 $\mathrm{mm}$ e $>3 \mathrm{~mm}$. As correlações entre a quantidade de raízes dessa cultura e o volume de poros do solo foram idênticas às do cacaueiro, mas não houve significância na classe de raízes < 1 mm. Previtali (2007) verificou, em mudas de pupunheira, após três meses do plantio, haver correlação positiva da quantidade

Tabela 2. Massa seca de raízes por diâmetro em diferentes profundidades e distâncias (D1 e D2) da planta de pupunheira

\begin{tabular}{|c|c|c|c|c|}
\hline \multirow{3}{*}{ Profundidade } & \multirow{3}{*}{ Distância } & \multicolumn{3}{|c|}{ Massa seca $\left(\mathrm{g} \mathrm{dm}^{-3}\right)$} \\
\hline & & $<1,0 \mathrm{~mm}$ & $1,0-3,0 \mathrm{~mm}$ & $>3,0 \mathrm{~mm}$ \\
\hline & & \multicolumn{3}{|c|}{$\mathrm{g} \mathrm{dm}^{-3}$} \\
\hline $0-10$ & D1 & $1,80 \mathrm{Aa}$ & $4,65 \mathrm{~A} \mathrm{a}$ & $9,36 \mathrm{Aa}$ \\
\hline $10-20$ & & $0,46 \mathrm{Aa}$ & $1,08 \mathrm{~B} \mathrm{a}$ & $2,42 \mathrm{Ba}$ \\
\hline $20-30$ & $(0,25 \mathrm{~m})$ & $0,23 \mathrm{Aa}$ & $0,30 \mathrm{Ba}$ & $0,42 \mathrm{Ba}$ \\
\hline \multirow[t]{2}{*}{$30-40$} & & $0,05 \mathrm{Aa}$ & $0,11 \mathrm{Ba}$ & $0,14 \mathrm{Ba}$ \\
\hline & Total D1 & $2,54 \mathrm{a}$ & $6,14 \mathrm{a}$ & $12,34 \mathrm{a}$ \\
\hline $0-10$ & & $1,75 \mathrm{Aa}$ & $5,50 \mathrm{~A} \mathrm{a}$ & $9,92 \mathrm{~A} \mathrm{a}$ \\
\hline $10-20$ & D2 & $0,84 \mathrm{Aa}$ & $1,08 \mathrm{Ba}$ & $2,14 \mathrm{Ba}$ \\
\hline $20-30$ & $(0,75 \mathrm{~m})$ & $0,14 \mathrm{Aa}$ & $0,22 \mathrm{Ba}$ & $0,32 \mathrm{Ba}$ \\
\hline \multirow[t]{2}{*}{$30-40$} & & $0,05 \mathrm{Aa}$ & $0,22 \mathrm{Ba}$ & $0,40 \mathrm{Ba}$ \\
\hline & Total D2 & $2,77 \mathrm{a}$ & $7,02 \mathrm{a}$ & $12,77 \mathrm{a}$ \\
\hline
\end{tabular}

Médias seguidas de mesma letra maiúscula na coluna, comparando as profundidades, e minúsculas na linha, comparando as distâncias, não diferem entre si a $5 \%$ de probabilidade de erro.

Tabela 3. Massa seca de raízes $\left(\mathrm{g} \mathrm{dm}^{-3}\right)$ por diâmetro em diferentes profundidades e distâncias (D1 e D2) da planta de açaizeiro

\begin{tabular}{|c|c|c|c|c|}
\hline \multirow{3}{*}{ Profundidade } & \multirow{3}{*}{ Distância } & \multicolumn{3}{|c|}{ Massa seca $\left(\mathrm{g} \mathrm{dm}^{-3}\right)$} \\
\hline & & $<1,0 \mathrm{~mm}$ & $1,0-3,0 \mathrm{~mm}$ & $>3,0 \mathrm{~mm}$ \\
\hline & & \multicolumn{3}{|c|}{$\mathrm{g} \mathrm{dm}^{-3}$} \\
\hline $0-10$ & D1 & $6,22 \mathrm{~A} \mathrm{a}$ & $8,25 \mathrm{~A} \mathrm{a}$ & $17,94 \mathrm{~A} \mathrm{a}$ \\
\hline $10-20$ & & $1,37 \mathrm{Ba}$ & $2,57 \mathrm{Ba}$ & $10,06 \mathrm{~B} \mathrm{a}$ \\
\hline $20-30$ & $(0,25 \mathrm{~m})$ & $0,83 \mathrm{Ba}$ & $0,79 \mathrm{Ba}$ & $1,49 \mathrm{Ca}$ \\
\hline \multirow[t]{2}{*}{$30-40$} & & $0,28 \mathrm{Ba}$ & $0,40 \mathrm{Ba}$ & $1,53 \mathrm{Ca}$ \\
\hline & Total D1 & $8,70 \mathrm{a}$ & $12,01 \mathrm{a}$ & $31,01 \mathrm{a}$ \\
\hline $0-10$ & & $7,65 \mathrm{Aa}$ & $6,62 \mathrm{~A} \mathrm{a}$ & $13,37 \mathrm{~A} \quad \mathrm{~b}$ \\
\hline $10-20$ & D2 & $1,70 \mathrm{Ba}$ & $2,02 \mathrm{Ba}$ & $7,99 \mathrm{AB} a$ \\
\hline $20-30$ & $(0,75 \mathrm{~m})$ & $0,72 \mathrm{Ba}$ & $0,62 \mathrm{Ba}$ & $2,58 \mathrm{BCa}$ \\
\hline \multirow[t]{2}{*}{$30-40$} & & $0,30 \mathrm{Ba}$ & $0,66 \mathrm{Ba}$ & $0,95 \mathrm{Ca}$ \\
\hline & Total D2 & $10,36 \mathrm{a}$ & $9,92 \mathrm{a}$ & $24,87 \mathrm{a}$ \\
\hline
\end{tabular}

Médias seguidas de mesma letra maiúscula na coluna, comparando as profundidades, e minúsculas na linha, comparando as distâncias, não diferem entre si a $5 \%$ de probabilidade de erro. 
de raízes com a macroporosidade e negativa com a microporosidade do substrato de cultivo, sendo as mesmas representadas, respectivamente, pelo volume de poros maior e menor que $0,03 \mathrm{~mm}$.

Com o açaizeiro, as correlações entre a quantidade de raízes e as variáveis do solo repetem-se quanto aos teores de silte e de argila e com o volume de poros grandes, mas houve relação negativa com o grau de floculação e com a densidade do solo em todas as classes de diâmetro de raízes. Também houve correlação positiva da quantidade de raízes com a condutividade hidráulica em todas as classes de diâmetro. Essa cultura apresentou o maior número de correlações diretas entre a quantidade de raízes e as variáveis do solo, envolvendo as três classes de diâmetro de raízes.

Quando se tomam os dados referentes às raízes das três culturas em conjunto, verifica-se a existência de correlações diretas (positivas) com o teor de areia grossa e a

Tabela 4. Coeficientes de correlação linear entre o diâmetro de raízes $\left(\mathrm{g} \mathrm{dm}^{-3}\right)$ e as variáveis físicas do solo ${ }^{(1)}$, considerando as médias das profundidades e as médias entre as duas distâncias entre plantas das culturas estudadas $(\mathrm{n}=16)$

\begin{tabular}{|c|c|c|c|c|c|c|c|c|c|c|c|c|c|}
\hline \multirow{2}{*}{ Culturas } & \multirow{2}{*}{ Areg } & \multirow{2}{*}{ Aref } & \multirow{2}{*}{ Sil } & \multirow{2}{*}{ Arg } & \multirow{2}{*}{ GF } & \multirow{2}{*}{ Dp } & \multirow{2}{*}{ Ds } & \multirow{2}{*}{ Ko } & \multicolumn{5}{|c|}{ VPT } \\
\hline & & & & & & & & & $>0,15$ & $>0,05$ & $>0,03$ & $<0,03$ & $<0,05$ \\
\hline \multicolumn{14}{|l|}{ Cacaueiro } \\
\hline Raízes <1mm & 0,76 & 0,03 & $-0,55$ & $-0,73$ & $-0,09$ & 0,10 & $-0,67$ & 0,42 & 0,73 & 0,79 & 0,73 & 0,41 & 0,51 \\
\hline Raízes1-3mm & 0,67 & $-0,01$ & $-0,42$ & $-0,65$ & $-0,06$ & 0,22 & $-0,48$ & 0,25 & 0,60 & 0,60 & 0,59 & 0,30 & 0,42 \\
\hline Raízes >3mm & $\mathbf{0 , 5 4}$ & 0,26 & $-0,55$ & $-0,61$ & $-0,19$ & $-0,08$ & $-0,52$ & 0,33 & 0,61 & 0,62 & 0,64 & 0,31 & 0,46 \\
\hline \multicolumn{14}{|l|}{ Pupunheira } \\
\hline Raízes <1mm & 0,72 & $-0,68$ & $-0,25$ & $-0,51$ & $-0,07$ & 0,00 & 0,06 & 0,35 & 0,40 & 0,40 & 0,30 & 0,40 & 0,25 \\
\hline Raízes1-3mm & 0,86 & $-0,64$ & 0,00 & $-0,76$ & $-0,28$ & 0,00 & $-0,64$ & $\mathbf{0 , 7 2}$ & 0,84 & 0,86 & 0,72 & 0,29 & 0,34 \\
\hline Raízes >3mm & $\mathbf{0 , 8 4}$ & $-0,41$ & $-0,21$ & $-0,73$ & $-0,48$ & 0,00 & $-0,60$ & $\mathbf{0 , 8 5}$ & 0,93 & 0,93 & 0,85 & 0,11 & 0,36 \\
\hline \multicolumn{14}{|l|}{ Açaizeiro } \\
\hline Raízes <1mm & $\mathbf{0 , 8 0}$ & $-0,30$ & $-0,32$ & $-0,69$ & $-0,70$ & 0,18 & $-0,68$ & 0,90 & 0,79 & 0,72 & 0,71 & 0,19 & 0,63 \\
\hline Raízes1-3mm & $\mathbf{0 , 7 7}$ & $-0,17$ & $-0,08$ & $-0,88$ & $-0,68$ & 0,17 & $-0,64$ & 0,66 & 0,68 & 0,76 & 0,75 & $-0,05$ & 0,41 \\
\hline Raízes >3mm & 0,67 & $-0,19$ & 0,07 & $-0,88$ & $-0,73$ & 0,19 & $-0,54$ & 0,68 & 0,66 & 0,74 & 0,75 & $-0,05$ & 0,45 \\
\hline
\end{tabular}

Valores acima de 0,496 são significativos (em negrito) para rejeitar a hipótese de correlação até 0,05 de p e os acima de 0,623 a 0,01 de p pelo teste $\mathrm{t}$.

${ }^{(1)}$ Areg = teor de Areia fina $\left(\mathrm{g} \mathrm{kg}^{-1}\right)$; Aref = teor de Areia fina $\left(\mathrm{g} \mathrm{kg}^{-1}\right)$; Sil = teor de Silte $\left(\mathrm{g} \mathrm{kg}^{1}\right)$; Arg = teor de Argila $\left(\mathrm{g} \mathrm{kg}^{-1}\right)$; Gf $=\mathrm{Grau} \mathrm{de}$ floculação $\left(\mathrm{g} \mathrm{kg}^{-1}\right) ; \mathrm{Dp}=$ Densidade de partículas $\left(\mathrm{kg} \mathrm{m}^{-3}\right) ; \mathrm{Ds}=$ Densidade do solo $\left(\mathrm{kg} \mathrm{m}^{-3}\right) ; \mathrm{Ko}=$ Condutividade hidráulica do solo saturado $\left(\mathrm{cm} \mathrm{h}^{-1}\right)$; e VPT $=$ Volume de poros $\left(\mathrm{m}^{3} \mathrm{~m}^{-3}\right)$ por tamanho $(\mathrm{mm})$.

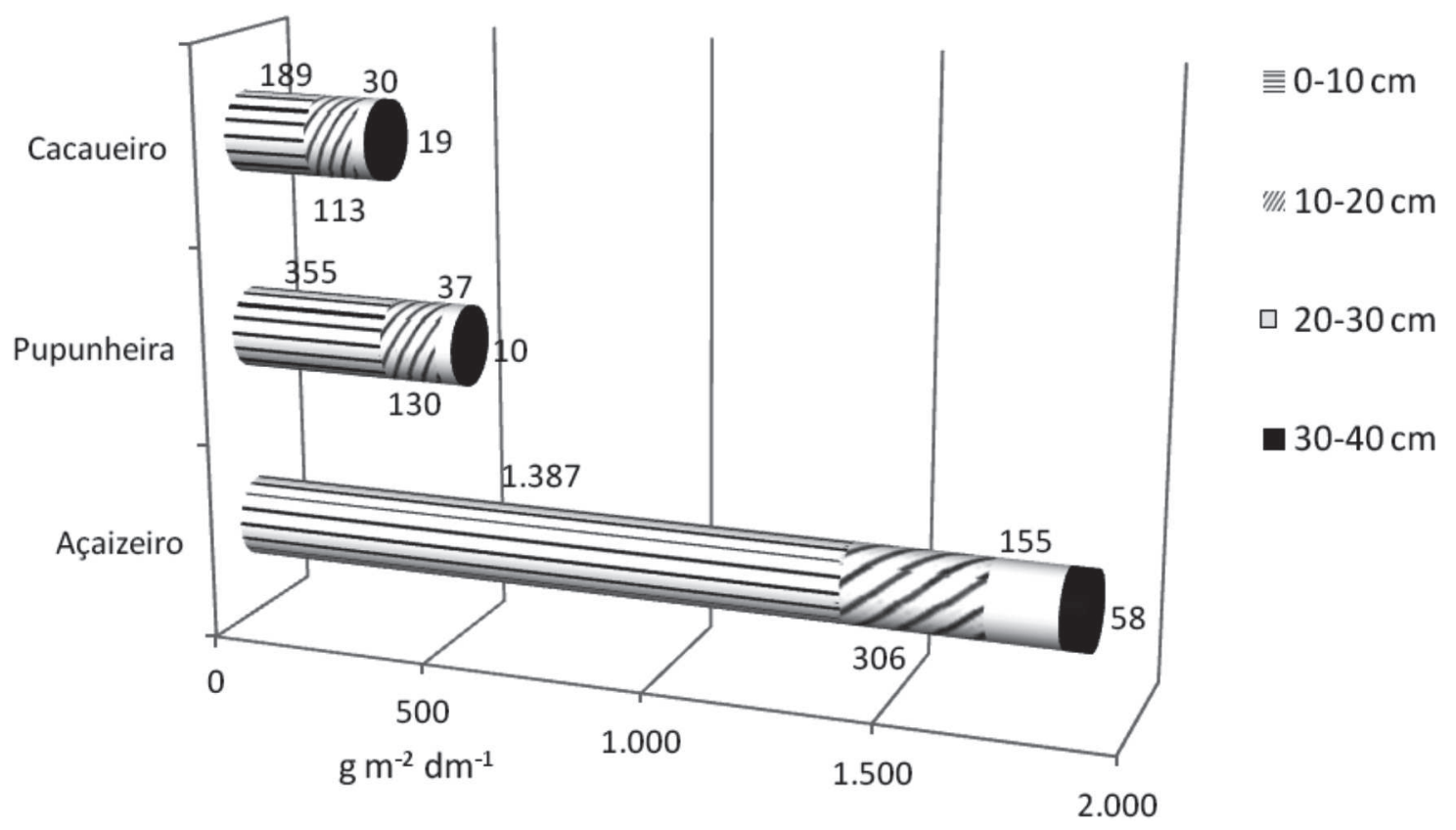

Figura 1. Massa seca de raízes de cacaueiro, pupunheira e açaizeiro com oito anos de idade, em diferentes profundidades. 
quantidade de poros grandes; e correlações inversas (negativas) com o teor de argila e a densidade do solo.

A existência de correlação positiva entre o teor de areia e a quantidade de todas as classes de diâmetro de raízes das três culturas pode ser explicada pelo fato de o teor de areia estar relacionado com a ocorrência de poros grandes, como verificado por Augusto et al. (2004), que encontraram relações diretas entre a quantidade de areia grossa e os diversos tamanhos de poros grandes, e também com a condutividade hidráulica, e inversas com o teor de argila e a densidade do solo. Desse modo, pode-se argumentar que a textura do solo e a ocorrência de poros grandes nas condições do estudo permitiram que as raízes pudessem se desenvolver, o que também fora constatado na cultura do milho por Shierlaw \& Alston (1984) ao estudarem a absorção de fósforo.

Certamente um bom desenvolvimento das raízes também poderia ocorrer, e talvez até em maior intensidade, se o solo fosse mais argiloso e houvesse agregação suficiente para formação de macroporos, o que viria a depender da natureza da quantidade de argila (Kiehl, 1979) e dos minerais que a constituem. No caso do solo estudado, de textura franco-arenosa, como a quantidade de argila é baixa e constituída principalmente de caulinita e óxidos de Fe e Al, que possuem baixa CTC (Sanchez, 1981), com pequena capacidade de formação de agregados (Kiehl, 1979), a existência de macroporos está relacionada ao teor de areia grossa. Assim, pode-se cogitar que há efeito recíproco entre o solo e as plantas por meio de suas raízes e das propriedades físicas do solo. O sistema radicular, quanto mais abundante, como é o caso do açaizeiro, concorre para a diminuição da densidade do solo que, em associação aos maiores teores de areia grossa e menores teores de argila, favorece a ocorrência de poros grandes e, consequentemente, de mais elevada condutividade hidráulica do solo quando saturado.

Relações entre a distribuição do tamanho de poros com a produtividade de gramíneas foram encontradas em Uruará - PA, por Martins et. al. (2000), os quais afirmaram que isso se dá pela adequação da retenção de água e da respiração das plantas, causada pelas características favoráveis do solo. Por outro lado, Brito et al. (2000) relataram que o desenvolvimento do capim-braquiarão (Brachiara brizantha, acesso BB 4219) parece estar relacionado à porosidade de aeração na parte mais superficial do solo, independentemente do seu tipo. Já Shierlaw e Alston (1984) verificaram que as raízes finas têm diâmetro semelhante ao dos poros do solo, indicando que há relação entre o tamanho dos poros e o desenvolvimento de raízes de tamanho compatível.

Pelos dados apresentados, é possível argumentar que as relações entre a quantidade de raízes e as propriedades físicas do solo decorrem de influência recíproca, pois tanto essas propriedades influenciam o desenvolvimento das raízes como elas podem influenciar aquelas, tendo efeito sobre o seu próprio crescimento.

Uma aplicação que pode decorrer do efeito positivo das raízes sobre o solo é o benefício que uma planta traz sobre o desenvolvimento de outra que lhe esteja associada, demonstrando a importância dos consórcios e dos sistemas agroflorestais (Haag 1997). A cultura do cacaueiro pode ser beneficiada pelo consórcio com o açaizeiro, em condições de solo semelhantes ao da área do experimento utilizado, devido ao sistema radicular abundante e com raízes grossas dessa cultura, por contribuir com a formação de poros grandes e facilitar a aeração, especialmente no período chuvoso, em que há excesso de água (Mendez, 2000). É de se esperar que em solos mais argilosos, especialmente os que possuam minerais de argila que facilitam a macroagregação, os efeitos das raízes sobre a densidade do solo e a porosidade, como os encontrados neste estudo, sejam mais intensos.

\section{CONCLUSÕES}

O açaizeiro apresenta o dobro da quantidade de raízes da pupunheira e 10 vezes mais que a do cacaueiro, variando, nas três culturas, com a profundidade do solo, concentrando-se em mais de $50 \%$ na camada superficial do solo.

Como a quantidade de raízes finas do cacaueiro e do açaizeiro é mais abundante na superfície do solo, a adubação de manutenção nessas culturas deve ser feita aplicando o adubo em cobertura. No caso do cacaueiro, devese considerar a maior concentração dessas raízes na superfície mais distante do tronco.

Nas três culturas, a quantidade de raízes, independentemente do diâmetro, correlaciona-se diretamente com o teor de areia grossa e indiretamente com o de argila e a densidade do solo.

A quantidade de raízes nas culturas do cacaueiro e do açaizeiro correlaciona-se diretamente com o volume de poros grandes (a partir de 0,03 mm de diâmetro) nas três classes de diâmetro de raízes, enquanto na cultura da pupunheira apenas nas classes de raízes maiores que $1,0 \mathrm{~mm}$.

$\mathrm{O}$ açaizeiro, além de apresentar entre as três culturas o sistema radicular mais abundante, tem o maior número de correlações entre a quantidade de raízes e as propriedades físicas do solo. Essa cultura, por apresentar sistema radicular mais abundante e com condições de influir positivamente na estrutura do solo, pode, quando em consórcio, beneficiar outras culturas. 


\section{REFERÊNCIAS}

Augusto SG, Martins PFS \& Góes AVM (2004) Propriedades físicas do solo sob as culturas do cacau (Theobroma cacao L.), da pupunha (Bactris gaesipaes H. B.) e do açaí (Euterpe oleraceae Mart.). Revista de Ciências Agrárias, 42:221-223.

Bohm W (1979) Methods of studying root systems. Berlim, Springer-verlag. $188 \mathrm{p}$.

Bovi MLA, Spiering SH \& Barbosa AMM (1999) Densidade radicular de progênies de pupunheira em função de adubação NPK. Horticultura Brasileira, 17:186-193.

Brito LA, Farias SKP, Martins PFS \& Veiga JB (2000) Efeitos de gramíneas forrageiras sobre a porosidade do solo em Uruará (Transamazônica), Pará. In: International Symposium: Soilpastures in Intertropical Areas 2000, Brasília. Proceedings, Embrapa Cerrados/IRD. CD-ROM.

Chaimsohn FP, Villalobos E \& Urpi JM (2007) O fertilizante orgânico aumenta a produção de raízes em plantas de pupunha (Bactris gasipaes K.). Revista Agronomía Costarricense, 31:5764.

Cotta MK, Jacovine LAG, Paiva HN, Soares CPB, Filho ACV \& Valverde SR (2008) Quantificação de biomassa e geração de certificado de emissões reduzidas no consorcio seringueira-cacau. Revista Árvore, 32:969-978.

Ferreira SAN, Clement CR \& Ranzani G (1980) Contribuição para o conhecimento do sistema radicular da pupunheira (Bactris gasipaes H.B.K. = Guilielma gasipaes - H.B.K - Bailey) . I. Solo Latossolo Amarelo, Textura Média. Acta Amazonica, 10:245-249.

Haag D (1997) Root distribution patterns in a polycultural system with local tree crops on an acid upland soil in central Amazonian. Master in Science Thesis. Lehrstuhl für Bodenkunde und Bodengeographie der Universität, Bayreuth. 171p.

Instituto Brasileiro de Geografia e Estatística - IBGE (2006) Censo Agropecuário. Disponível em: < http://www.sidra.ibge.gov.br/ bda/tabela/listabl.asp? $\mathrm{z}=\mathrm{t} \& \mathrm{c}=1821>$. Acessado em: 28 de março de 2011.
Kiehl EJ (1979) Manual de edafologia. São Paulo, Agronômica Ceres. 262p.

Martins PFS, Leoplodino ALM \& Veiga JB (2000) Relações solopastagem em Uruará (Transamazônica), Pará. In: International Symposium: Soil-pastures in Intertropical Areas 2000, Brasília. Proceedings, Brasília, Embrapa Cerrados/IRD. CD-ROM.

Mendez JGR (2000) Variabilidade das propriedades morfológicas e físico-hídricas de um solo da Estação de Recursos Genéticos do cacau "José Haroldo", em Marituba-Pará. Dissertação de Mestrado. Faculdade de Ciências Agrárias do Pará, Belém. 99p.

Neves ADS \& Barbosa RCM (1983) Levantamento detalhado dos solos do campo de introdução de Theobroma na Amazônia. Ilhéus, CEPLAC. 30p. (Boletim Técnico, 1).

Previtali RZ (2007) Crescimento de mudas de pupunheira (Bractis gasipaes Kunth) em substrato compactado. Dissertação de Mestrado. Instituto Agronômico, Campinas. 87p.

Sanchez PA (1981) Suelos del trópico: características y manejo. San José, IICA. 634p.

Selton JC, Mielniczuk J, Bayer C, Boeni M, Conceição PC, Fabrício AC, Macedo MCM \& Broch DL (2008) Agregação e estabilidade de agregados do solo em sistemas agropecuários em Mato Grosso do Sul. Revista Brasileira de Ciência do Solo, 32:11-28.

Shanley P \& Medina G (2005) Frutíferas e plantas úteis na vida amazônica. Belém, CIFOR \& Imazon. 304p.

Shierlaw J \& Alston AM (1984) Effect of soil compaction on root growth and uptake of phosphorus. Plant and Soil, 77:15-28.

Silva JVO (2009) Produção e partição de biomassa e nutrientes e parametrização de um sistema para recomendação de N, P e K para cacaueiros. Dissertação de Mestrado. Universidade Estadual de Santa Cruz, Ilheus. 85p.

Vega FVA, Bovi MLA, Godoy Júnior G \& Berton RS (2005) Lodo de esgoto e sistema radicular da pupunheira. Revista Brasileira de Ciência do Solo, 29:259-268. 